\title{
RADIO FREQUENCY COMMUNICATION BASED SAFETY AND SECURITY FOR FISHERMEN
}

\author{
S.Padma Priya Dharshinii ${ }^{1}$, P.Revathi ${ }^{2}$, K.Srri Vidyaa ${ }^{3}$,S.Jalaja ${ }^{4}$ \\ ${ }^{1-3}$ UG- Electronics And Communication Engineering, Anna University, Chennai, Tamil Nadu \\ ${ }^{4}$ Assistant Professor, Department Of ECE, Anna University, Chennai, Tamil Nadu
}

\begin{abstract}
Fishing is the activity of catching a fish in the sea. But this can be fatal. Because our fishermen knowingly or unknowingly cross the border and land up in other country's marine waters. In this paper a quick fix is given to issue 'Fishermen capture their spot in the ocean'. For this, the sea area is divided into three zones namely; safe, intermediate and danger. The boat is allowed to roam anywhere within the safety zone. If the boat reaches the intermediate zone the buzzer alert is given to the fishermen. If the boat reaches the danger zone, an intimation is given to the fishermen. Else the engine gets stopped automatically. Now the control of the boat goes to the control room. The different ranges are identified using Received Signal Strength Indicator(RSSI).
\end{abstract}

Keywords: Zones; Buzzer Alert; RSSI.

\section{INTRODUCTION}

The technology proliferation of Received Signal Strength Indication(RSSI) is used to provide location based positioning and time details in all climatic conditions and even anywhere at any time. This method focuses on implementing a border identification system for all boats. However, the existing system is not powerful enough to prevent the crime against fishermen as it gives only the information about the border identification but not about the exact distance that the boat has travelled from the border The proposed system's transmitter section includes ARDUINO microcontroller RSSI module, voice playback circuit and DC motor and the receiver section includes RSSI, PC as monitoring database in the control room of port. And we can send messages to the fishermen's home and control them through the Global System For Mobile Communication( GSM) module.

\section{EXPERIMENTAL METHODOLOGY}

In this proposed system, Received Signal Strength Indicator(RSSI) is used to track the boat location at any time. The RSSI technology helps in reading the boat and tells the localization of the boat. Received signal strength is a measure of power level that a RF client device is receiving from an access point. The received signal strength indicator will find the strength of the signal of Radio Frequency. Depending on the strength of the signal, the area is divided into safe, intermediate and danger zones. Based on the received signal we can find the boat location and intimate them about the location of the boat.

\section{Transmitter Section}

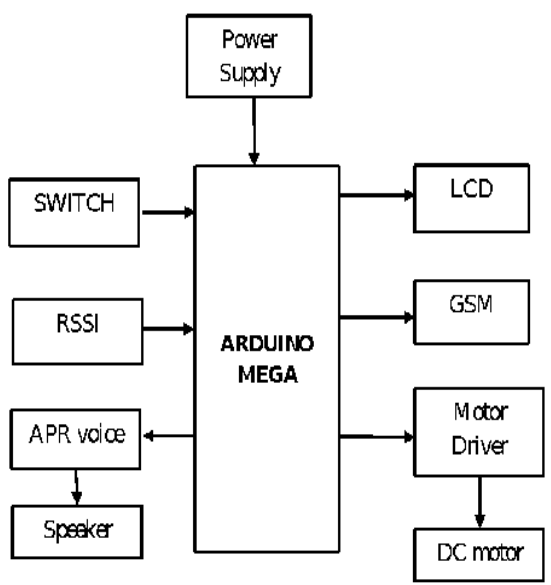


International Advanced Research Journal in Science, Engineering and Technology

Vol. 8, Issue 8, August 2021

DOI: $10.17148 /$ IARJSET.2021.8806

\section{Receiver Section}

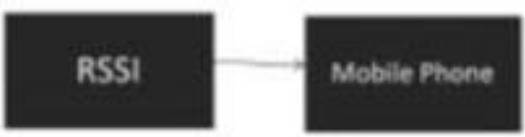

\section{Overall Architecture Diagram}

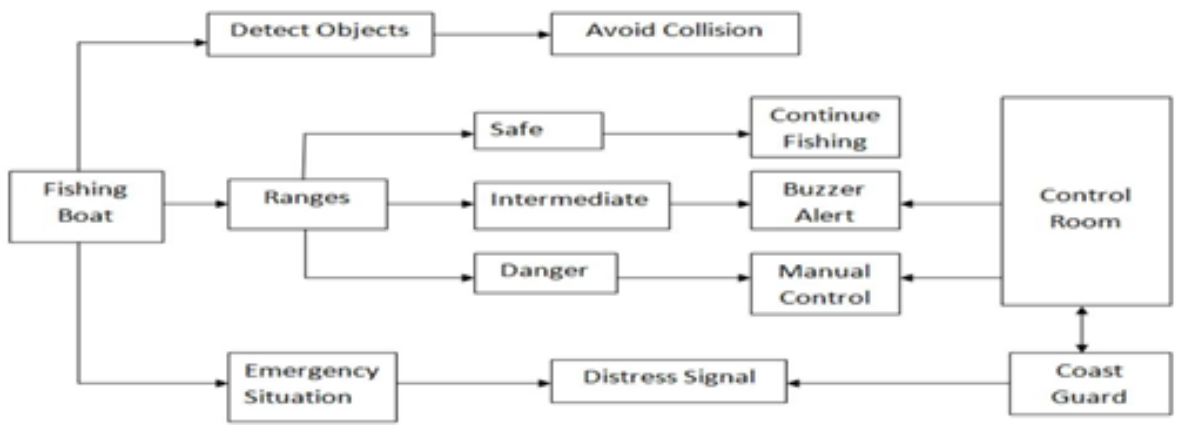

\section{RESULT}

Here the 4 stages of the boat localization are displayed in LCD in the device including the initial stage. The upcoming images show the different warning notifications given to the fishermen when the boat is in each zone.

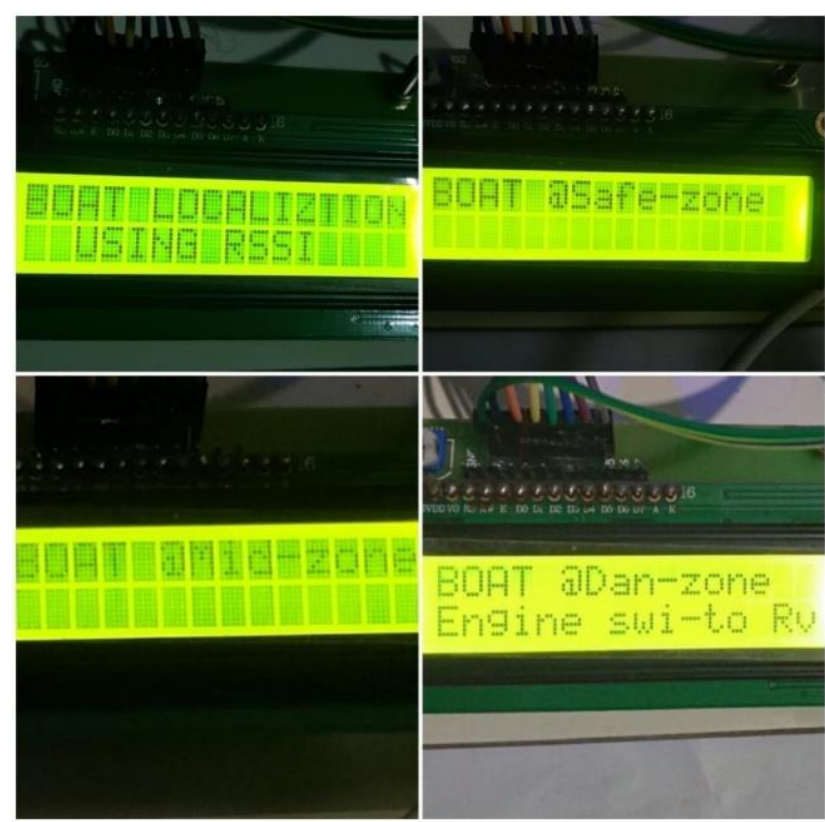




\section{International Advanced Research Journal in Science, Engineering and Technology}

Vol. 8, Issue 8, August 2021

DOI: $10.17148 /$ IARJSET.2021.8806

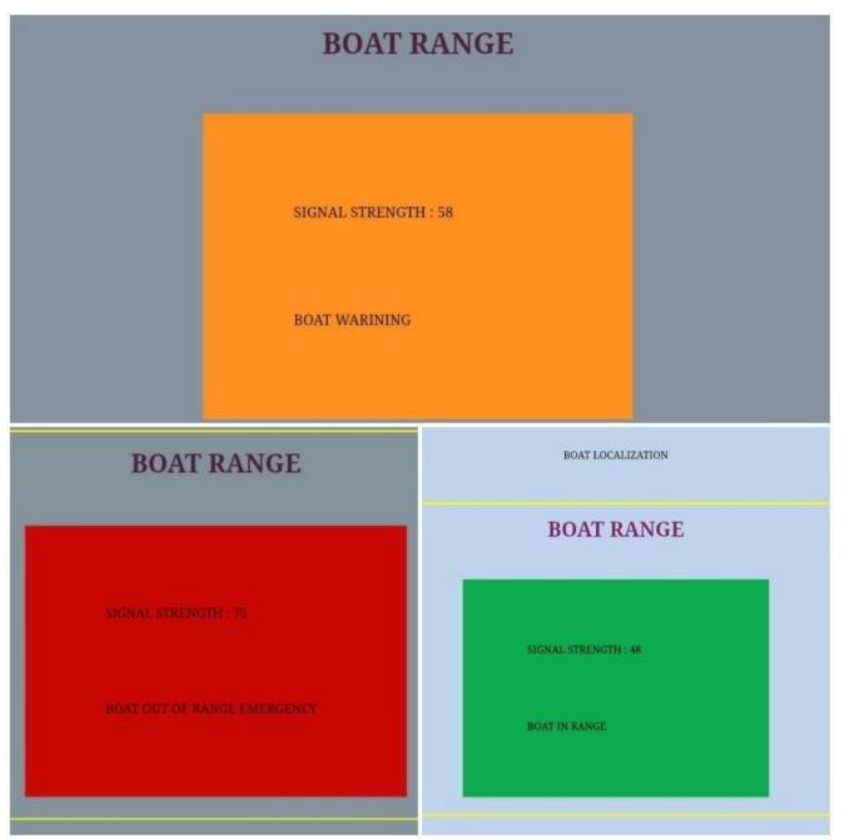

That is, If the boat is in the safe zone the green colour of notification is given.If the boat is in the mid zone the orange colour of notification is given.If the boat is in the danger zone,red colour of notification is given $\&$ also at this stage the boat is automatically stopped.

\section{CONCLUSION}

The fishermen boats broadcast its information and display their location. A pure RF based relative localization and tracking system by using TRIZONAL IMPLEMENTATION, thereby preventing the fishermen from crossing the border in sea. This system also provides an alert incase of emergency. If the boat reaches a specified region the control of the boat is under the control room. This system also helps to detect obstacles in the path.

\section{REFERENCES}

1. 'Signal strength based indoor and outdoor localization scheme in ZigBee sensor networks' . Wen-hsing Kuo , Yung-sheng chen , Kui-tai cheng, and Tai-wei Lu, IAENG international journal of computer science , 2016.

2. 'Using RSSI value for distance evaluation in wireless sensor networks based on ZigBee', k. benkic, M.Malajner , P.Planinsic, z. cucej , 2000 .

3. 'On-line RSSI-Range model learning for Target Localization and Tracking', Jose Ramiro Martinez-de dios, Anibal Ollero, Francisco Jose Fernandez, and Carolina Regoli, 2017.

4. 'An Indoor positioning Algorithm Using Bluetooth Low Energy RSSI', Song Chai, Renbo An, and Zhengzhong Du, International Conference on Advanced Material Science and Environment Engineering, 2016.

5. 'RSSI-based relative localization for mobile robots', Luis Oliveria, Hongbin Li, Luis Almeida, 2013.

6. Soundharya B M; Yogeshwaran R; Tharanish Krishna A D; Vinitha V. "Automatic Check Post and E-Toll Payment System". International Research Journal on Advanced Science Hub, 3, Special Issue ICARD-2021 3S, 2021, 57-62. doi: 10.47392/irjash.2021.064

7. Qurratul Aini; Sabah Syed Nasirullah; Sumaya Tazeen; Mirza Younus Ali Baig; Lochan Rampal. "Investigation of intelligent transport system with optical vehicle-to-vehicle communication". International Research Journal on Advanced Science Hub, 2, Special Issue ICAMET 10S, 2020, 132-137. doi: 10.47392/irjash.2020.222

8. C.H. Knapp, G.C. Carter,'The Generalized Correlation Method for Estimation of Time Delay," IEEE Trans. On Acoustics, Speech and Signal Processing, Vol. ASSP-24, no.4, pp.320-327, 1976

9. H.Krim, and M. Viberg, "Two Decades of Array Signal Processing Research," IEEE Signal Processing Magazine, pp. $67-1996$

10. V. Cizek, "Discrete Hilbert transform,” IEEE Trans on Audio Electro- Acoustics, vol. AU-18, no.4, Dec 1970, pp.340-343.

11. Ralph O. Schmidt, "Multiple emitter location and signal parameter estimation." IEEE Trans on Antennas and Propagation, 1986

12. Bahl, P., Padmanabhan, V.N.: RADAR: an in-building RF-based user location and tracking system. In: Proc. of the IEEE INFOCOM

13. Kim, S.B., Park, C., Kang, D.Y.: An efficient positioning algorithm using ultrasound and RF. International Journal of Control, Automation and Systems

14. Sithole, G.; Zlatanova, S. Position, Location, Place and Area: An Indoor Perspective. ISPRS Ann. Photogramm. Remote Sens. Spat. Inf. Sci. 2016 ,

15. Errington, A.F.C.; Daku, B.L.F.; Prugger, A.F. Initial Position Estimation Using RFID Tags: A Least-Squares Approach. IEEE Trans. Instrum. Meas. 2010

16. Tesoriero, R.; Gallud, J.; Lozano, M.; Penichet, V.R. Tracking autonomous entities using rfid technology. IEEE Trans. Consum. Electron 